\title{
Omental Patch Repair for Duodenal Ulcer Perforation- Analysis of Factors Affecting Outcome: A Prospective Study
}

\author{
Nitin Agarwal ${ }^{1 *}$, Arun Gupta ${ }^{2}$, BK Jain ${ }^{2}$ and Ram Niwas Saran ${ }^{3}$ \\ ${ }^{1}$ Department of Surgery, Renal Transplant Unit, Postgraduate Institute of Medical Education and Research (PGIMER) and \\ Dr. Ram Manohar Lohia Hospital (RMLH), Delhi 110001, India \\ ${ }^{2}$ Director-Professor, Department of Surgery, University College of Medical Sciences and Guru Tegh Bahadur Hospital, Delhi, \\ India \\ ${ }^{3}$ Former Postgraduate resident, Department of Surgery, University College of Medical Sciences and Guru Tegh Bahadur \\ Hospital, Delhi, India
}

Received: March 13, 2018; Accepted: April 06 2018; Published: April 10, 2018

*Corresponding author: Nitin Agarwal, Department of Surgery, Renal Transplant Unit, Postgraduate Institute of Medical Education and Research (PGIMER) and Dr. Ram Manohar Lohia Hospital (RMLH), Delhi 110001, India, Email: drnitinagarwal76@gmail.com

\begin{abstract}
Background/Objectives: Primary repair of duodenal perforations with the omental patch technique has re-emerged as the mainstay of treatment of this widely-prevalent condition, especially in our country. We have prospectively studied factors affecting outcome (morbidity, mortality) of duodenal ulcer perforations treated by omental patch technique, and have also attempted to study the efficacy of contemporary scoring systems (Haceteppe, APACHE II, Mannheim Peritonitis Index, Jabalpur score) in predicting outcome.
\end{abstract}

Methods: One hundred consecutive patients of non-traumatic duodenal ulcer perforations (NTDUP) over a 2-year period were recruited for this prospective study at a tertiary care hospital in Delhi, India. Clinical and laboratory data, and, outcome, were recorded; all patients were treated with omental patch repair.

Results: In 100 patients, there were 97 male (mean age $=40.8 \pm$ 14.2 years) and 3 female (mean age $=38.3 \pm 12.6$ ). Fourteen patients recovered completely, 86 had complications; of the latter five died. Age, serum creatinine, and perforation size were associated with unfavourable outcome $(\mathrm{p}=0.015,0.000,0.013$ respectively; students t-test). Presence of hypotension, serum creatinine, perforationoperation interval (PO), and perforation size, were associated with mortality alone $(\mathrm{p}=0.000,0.001,0.001,0.000$ respectively; student's t-test). Age, serum creatinine, $\mathrm{PO}$, and perforation size had correlation with longer hospital stay $(\mathrm{p}=0.044,0.005,0.012$, 0.003 respectively; Pearson's coefficient). Using receiver operating characteristic (ROC) curves, only the APACHE II and the Jabalpur scoring systems accurately predicted poor outcome.

Conclusions: Omental patch is a safe and effective method of closure of duodenal perforations. Other procedures may be combined if high-risk factors are identified, e.g., large perforation size. The Jabalpur score is a simple tool in large emergency rooms with limited facilities.

\section{Introduction}

The two most common causes of secondary peritonitis are small bowel and gastroduodenal perforation, especially in the developing world. In many studies, duodenal perforation is the most common cause [1-5].

At some point of time, omental patch repair of duodenal ulcer perforations was replaced by definitive acid-reduction procedures because of the high rates of recurrence. But with rapid and vast improvements in proton pump inhibitory agents, and, efficacious anti-Helicobacter pylori regimens, this may no longer be true [6-8]. Omental patch repair of duodenal ulcer perforation is both simpler than and as effective as definitive ulcer surgery in the emergency situation [9]. Perforations larger than $3 \mathrm{cms}$ have also been reported to be successfully repaired with this technique [10]. All these considerations have led to the resurgence of this technique.

Mortality due to ulcer perforation treated by simple closure and/or other methods is still around 10\% [11-13]. Factors reported to affect mortality in duodenal ulcer perforations in other series are old age, co-morbidity, preoperative hypotension, large size of the perforation, delay in presentation, and, delay in operation [14-18].

This prospective study was designed to study the morbidity and mortality in patients with non-traumatic duodenal ulcer perforation (NTDUP) treated by omental patch repair at a tertiary care centre in north India, and to correlate clinical, laboratory, and, operative factors with outcome. The efficacy of contemporary scoring systems (Haceteppe, APACHE II, Mannheim Peritonitis Index, Jabalpur score) in predicting outcome in our patients was also assessed. 


\section{Methods}

This prospective study was carried out in 100 consecutive patients operated for duodenal ulcer perforation over a period of 2 years in the Department of Surgery of a tertiary teaching hospital in Delhi, India. All patients above 18 years of age with non-traumatic duodenal ulcer perforation were included in the study. Patients who underwent an operation outside our hospital and were referred to us for tertiary care (treatment of complications, ventilatory support etc.) were excluded.

The parameters recorded were time of onset of disease, chronicity of pain, history of ulcerogenic agents (smoking alcohol, non-steroidal anti-inflammatory drugs, steroids), and, history of co-morbid conditions. In all patients, the pulse rate, respiratory rate, and, the blood pressure, at presentation, were recorded. The incidence of hypotension (mean arterial blood pressure $<60 \mathrm{mmHg}$ ) was also recorded. At admission, the following investigations were performed, i.e., haemoglobin, hematocrit, total leucocyte count, random blood sugar, blood urea, serum creatinine, serum electrolytes, serum albumin, chest and abdominal radiographs, electrocardiogram and arterial blood gas.

The admitted patients were adequately resuscitated and prepared for operation. A broad-spectrum third-generation cephalosporin with metronidazole was administered intravenously in all. A central venous line was inserted whenever deemed necessary. At exploration, the findings recorded were extent of peritonitis - localized or generalised, the site and size of the perforation. The peritoneal fluid was sent for microscopy, culture and sensitivity. The perforation was closed transversely with interrupted 2-0 polygalactin sutures after placing an omental patch over the perforation. Adequate drains were inserted after thorough peritoneal lavage.

The Hacettepe, APACHE-II, Mannheim Peritonitis Index (MPI), and Jabalpur Scores were calculated for all the patients from their examination findings and investigations.

Postoperative complications, if any, were recorded in all patients. The outcome in each patient was recorded as survival, survival with complications, or, death.

Length of hospital stay was calculated from the day of admission to the day of discharge or death of the patient. Patients were discharged when they were a febrile for at least 48 hours and when they accepted oral diet satisfactorily.

\section{Statistical Analysis}

Quantitative factors and qualitative factors affecting outcome were statistically analysed using unpaired student's t-test, and, Chi-Square and Fisher's exact tests, respectively. The relationship of various factors with the length of hospital stay was analysed by Pearson correlation. Stepwise regression analysis was used to find out if any of the factors independently affected the outcome. Analysis of various scoring systems was done by ROC curves.

\section{Results}

One hundred consecutive patients of non-traumatic duodenal ulcer perforation (NTDUP) during the study period (October 2004 to November 2006) were analyzed.

\section{Age and gender}

Perforation of the duodenum was seen in all age groups from the second to the seventh decade. The highest incidence was observed in the third to the sixth decade. The mean age of patients was $40.7 \pm 14.15$ years.

There were 97 male and 3 female patients. The mean age of the male patients was $40.77 \pm 14.25$ and a female patient was $38.33 \pm 12.58$ years. The male: female ratio was $32: 1$.

\section{Predisposing factors of NTDUP}

Eighty six percent of the patients were chronic smokers, mainly smoking 'bidi' (average 20/ day). Fifty-four patients had history of intake of alcohol for more than 5 years and out of these, $52(96.3 \%)$ were smokers too. Fifty three percent of patients gave a history of long standing abdominal pain suggesting chronic nature of the ulcer. Two percent of the patients were taking steroids for the last 6 months and 34\% patients gave a history of taking non-steroidal anti-inflammatory drugs (NSAIDS) occasionally during the last two weeks.

\section{Co-morbid conditions}

Two patients had associated respiratory tract ailments (COPD and bronchial asthma). One patient had history suggestive of coronary artery disease and one had diabetes mellitus.

Nine patients presented to the surgical emergency with hypotension, a mean arterial pressure (MAP) of $<60 \mathrm{~mm}$ of $\mathrm{Hg}$.

Ninety one percent of the patients presented and were operated upon more than 24 hours after onset of symptoms of peritonitis and $51 \%$ presented and were operated after 48 hours. The total leukocyte count was raised in $27 \%$ of the patients. Serum creatinine was estimated in all patients. It was raised $(>1.2$ $\mathrm{mg} / \mathrm{dl}$ ) in 24 patients.

Peritoneal cultures were positive in 15 patients. The organisms isolated were Escherichia coli in 11 patients, Streptococcus pyogenes in 2 patients, and, Citrobacter spp. and Staphylococcus aureus each, in 1 patient.

In 74 patients the size of the perforation was less than $0.5 \mathrm{~cm}$, in 28 patients it was between 0.5 and $1 \mathrm{~cm}$, and, in 8 patients it was more than $1 \mathrm{~cm}$.

\section{Outcome (Morbidity and Mortality)}

Fourteen patients had an uneventful recovery. Eighty one patients suffered from one or more complications. Five patients died, within 30 days of operation. All the patients who died had a perforation-operation interval of more than 48 hours (mean $108 \mathrm{hrs}$ ). Three of these five patients had unrecordable blood pressure at admission. Three patients had large ulcers $(1.5 \mathrm{cms}$ in size) and two of these leaked in the postoperative period. 


\section{Postoperative complications}

Surgical site infections (SSI) developed in 84 patients. Thirty-six patients had complete wound dehiscence which required secondary suturing. Intraabdominal abscess developed in 7 patients, out of which 2 patient's required operative drainage. Four patients had leak from the primary site (Table 1). Six patients were re-operated (four for leak, two for intraabdominal abscess). In patients who had leaked, resuturing of the perforation, lavage, and feeding jejunostomy was done in three, and, gastrojejunostomy in one patient. Four of these six reoperated patients had large ulcers $(1.5 \mathrm{~cm})$. Two patients, who were re-operated, had unrecordable blood pressure at admission.

\begin{tabular}{|c|c|}
\hline Table 1: Incidence of postoperative complications \\
\hline Complications & No. of cases \\
\hline Wound infection & 84 \\
\hline Wound dehiscence & 36 \\
\hline Respiratory infection & 9 \\
\hline Intraabdominal abscess & 7 \\
\hline Leak from primary site & 4 \\
\hline Gastrointestinal (GI) hemorrhage & 1 \\
\hline Occipital infarction & 1 \\
\hline
\end{tabular}

\section{Period of hospital stay}

The majority of patients were discharged within 14 days after surgery. Only 2 patients had prolonged hospital stay ( $>28$ days) due to re-operation.

\section{Statistical Analysis}

The relationship between factors like age, presence of hypotension, serum creatinine, white blood counts, perforationoperation interval and size of perforation, and, outcome of treatment was statistically analyzed using unpaired student t-test. The results are shown in Table 2.

As seen from the table there was a significant difference $(\mathrm{p}=0.015)$ in the mean age in the 86 patients who had morbidity or mortality ( $41.81 \mathrm{yrs}$ ) as compared to the 14 patients who went home without any complications (33.86 yrs). Similarly the mean serum creatinine in patients with complications or mortality was $1.348 \mathrm{mg} / \mathrm{dL}$, which was significantly $(\mathrm{p}=0.000)$ higher than values in patients who had no complications $(0.957 \mathrm{mg} / \mathrm{dL})$. A statistically significant difference was also observed in the mean size of the perforation $(0.54 \mathrm{~cm}$ in patients with no complications or death and $0.71 \mathrm{~cm}$ in those who had complications or died, $\mathrm{p}=0.013$ ). Though the mean arterial pressure was lower and the white cell counts higher in patients with poorer outcome, these differences did not reach statistical significance. All the deaths occurred in patients who presented late ( $>48$ hours) to the hospital. No significant difference was observed between the two groups with regard to perforation-operation interval.

Chi-Square \& Fisher's exact test was used to analyze qualitative data, i.e., the distribution of female patients, presence of co-morbid disease and history of chronic pain. No significant differences were found between the two groups.
Table 2: Factors affecting morbidity and mortality (unpaired students t- test)

\begin{tabular}{|c|c|c|c|c|c|}
\hline \multirow[t]{2}{*}{ Variable } & \multicolumn{2}{|c|}{$\begin{array}{l}\text { Patients with un- } \\
\text { eventful recovery } \\
\qquad(n=14)\end{array}$} & \multicolumn{2}{|c|}{$\begin{array}{l}\text { Patients with com- } \\
\text { plications or death } \\
\qquad(\mathrm{n}=86)\end{array}$} & \multirow[t]{2}{*}{$p$ value } \\
\hline & Mean & SD & Mean & SD & \\
\hline Age (yrs) & 33.86 & 9.719 & 41.81 & 14.481 & $0.015^{*}$ \\
\hline $\begin{array}{c}\text { MAP** } \\
\text { (mmHg) }\end{array}$ & 83.5 & 11.278 & 77.9 & 26.288 & 0.435 \\
\hline $\begin{array}{c}\text { S. creatinine } \\
(\mathrm{mg} \%)\end{array}$ & 0.957 & 0.1785 & 1.348 & 0.7069 & $0.000^{*}$ \\
\hline $\begin{array}{l}\text { White } \\
\text { cell count } \\
\text { (mm3) }\end{array}$ & 7100 & 2921.209 & 11513.44 & 12990.12 & 0.21 \\
\hline $\begin{array}{l}\text { P-O inter- } \\
\text { val` }^{\wedge} \text { hrs) }\end{array}$ & 46.07 & 18.244 & 55.01 & 33.342 & 0.331 \\
\hline $\begin{array}{l}\text { Size of } \\
\text { perforation } \\
(\mathrm{cm})\end{array}$ & 0.529 & 0.2128 & 0.709 & 0.3296 & $0.013^{*}$ \\
\hline${ }^{*}$ Significant & $\begin{array}{c}{ }^{* *} \text { mean } \\
\text { arterial } \\
\text { pres- } \\
\text { sure }\end{array}$ & & ration & ration int & \\
\hline
\end{tabular}

\section{Relationship of various factors with mortality alone}

A similar analysis done in the group of patients who died (Table 3) revealed that there were statistically significant differences in the mean arterial pressure, serum creatinine, size of the perforation and the perforation-operation interval, as compared to the patients who survived.

Among the qualitative factors, only the presence of co-morbid disease had significant ( $\mathrm{p}=0.012$ ) influence on the mortality.

Table 3: Relationship of various factors with mortality alone (unpaired student's t- test)

\begin{tabular}{|c|c|c|c|c|c|}
\hline \multirow{2}{*}{ Variable } & \multicolumn{2}{|c|}{ Survived (n=95) } & \multicolumn{2}{|c|}{ Expired (n=5) } & \multirow{2}{*}{ p-value } \\
\cline { 2 - 6 } & Mean & SD & Mean & SD & \\
\hline Age (yrs) & 40.58 & 14.24 & 43 & 13.49 & 0.711 \\
\hline $\begin{array}{c}\text { MAP** } \\
\text { (mmHg) }\end{array}$ & 81.11 & 20.98 & 32.6 & 45.37 & $0.000^{*}$ \\
\hline $\begin{array}{c}\text { S. creatinine } \\
\text { (mg\%) }\end{array}$ & 1.24 & 0.59 & 2.24 & 1.34 & $0.001^{*}$ \\
\hline $\begin{array}{c}\text { White cell } \\
\text { counts (mm3) }\end{array}$ & 10941.64 & 12427.84 & 10020 & 6445.31 & 0.87 \\
\hline $\begin{array}{c}\text { P-0 interval^ } \\
\text { (hrs) }\end{array}$ & 51.31 & 29.44 & 100.4 & 41.48 & $0.001^{*}$ \\
\hline $\begin{array}{c}\text { Size (cm) } \\
\text { *Significant }\end{array}$ & $\begin{array}{c}0.658 \\
\text { arterial } \\
\text { pressure }\end{array}$ & 0.294 & 1.18 & 0.438 & $0.000^{*}$ \\
\hline & \multicolumn{4}{|c|}{ perforation-operation interval } \\
\hline
\end{tabular}




\section{Relationship of various factors with hospital stay}

Using Pearson correlation of various factors with the length of hospital stay (Table 4), it was observed that age, serum creatinine, P-O interval and size of perforation had a significant positive correlation with the length of hospital stay.

On stepwise regression analysis, only serum creatinine was found to be an independent variable affecting the morbidity or mortality in these 100 patients of duodenal ulcer perforation. The length of hospital stay, however, was found to be independently affected by both serum creatinine, and, the size of the perforation.

Table 4: Relationship of various factors with hospital stay (Pearson correlation)

\begin{tabular}{|c|c|c|}
\hline \multirow{2}{*}{ Factors } & \multicolumn{2}{|c|}{ Hospital stay (days) (n=100) } \\
\cline { 2 - 3 } & Pearson correlation & $\begin{array}{c}\text { Significance } \\
\text { (2-tailed) }\end{array}$ \\
\hline Age (yrs) & 0.202 & $0.044^{*}$ \\
\hline MAP ** $(\mathrm{mmHg})$ & -0.127 & 0.208 \\
\hline S. creatinine (mg \%) & 0.279 & $0.005^{*}$ \\
\hline P-0 interval^ (hrs) & 0.25 & $0.012^{*}$ \\
\hline Size (cm) & 0.293 & $0.003^{*}$ \\
\hline *Significant & ${ }^{* *}$ mean arterial pres- & ^perforation-opera- \\
& sure & tion interval \\
\hline
\end{tabular}

\section{Analysis of the scoring systems}

APACHE II - All the 14 patients who had an uneventful recovery had a score of less than 10 at admission.

Mannheim Peritonitis Index scores - All the patients who died had a MPI score of greater than 14 at admission.

Jabalpur Scoring - The patients who recovered without complications tended to have lower scores. However, no clear trend was discernable for patients who had poor outcome.

Hacettepe scores - Only 8 patients had a score of less than 7.9. None of the patients who died had low scores.

The efficacy of these four systems in predicting mortality and morbidity was analyzed using ROC curves. The results are shown in Table 5. The APACHE-II scoring system and the Jabalpur scoring system were found to have values of area under the curve in the significant range $(>0.80)$, suggesting that these scoring systems can correctly predicts the mortality and morbidity in patients of N.T.D.U.P. The values in MPI and Hacettepe scoring systems were not found significant in this group of patients (Figure 1).

\section{Discussion}

\section{Demography and risk factors}

The age of patients of duodenal ulcer perforation has always been reported to be lower in Indian studies, as compared to their western counterparts. Boey et al in a series of 259 patients of


Figure 1: ROC curves depicting the efficacy of the four physiological scoring systems in predicting mortality and morbidity (area under the curve). Note that APACHE-II and Jabalpur scores have highly significant area under the curve

duodenal ulcer perforation reported a mean age of 51.3 years [19]. About a decade later, Hamby et al reported a mean age of 52 years in their series of 84 patients [20]. Over the past decade in developed countries, duodenal ulcer perforation is largely a disease of the elderly due to vastly improved proton pump inhibitory agents and anti-Helicobacter pylori drugs. In India, the mean age has been reported to be from 37 years to 42 years $[12,18,21]$. The mean age of presentation in our series was 40.7 years, which was in concurrence with other Indian authors. This would be expected to lead to a decrease in the mortality rate.

The gender difference in this disease is well known. But the male: female ratio was exceptionally high in our series (32:1). Probably in the poor population that frequents our institute, women are late in bringing forth their illness. Though chronic smoking (86\%), alcohol intake (54\%), and, nonsteroidal antiinflammatory drug (NSAIDs) intake (34\%) was prevalent in our patients, none of these factors had a statistical bearing on the outcome. The presence of co-morbid disease was, however, associated with mortality. The influence of smoking on duodenal ulcer perforations has been studied by Svanes et al (1997), who found that $96 \%$ (168 out of 175 ) of patients were smokers, and that smoking increased the risk of ulcer perforation 10-fold in a dose-response relationship [22]. Alcoholism has been reported to be common in these patients18, but not independently causative. Of late, NSAIDs have emerged as the most important causative factor in gastroduodenal perforation, especially in elderly persons. Between 1960 and 1980, the incidence of perforations fell among men of all ages living in Scotland. Among the women below 65 years of age, the incidence was steady, but in women over 65 there was a rise of $200 \%$ [23]. There is a strong suggestion that a major factor in this rise among older women is the steady increase in the use of the NSAIDs [24].

\section{Preoperative Status}

Over $90 \%$ of the patients in this series were operated upon after a delay of 24 hours, while $50 \%$ of the patients were operated after 48 hours of the onset of perforation. Despite this, $66 \%$ of 
the patients had a leucocyte count within the normal range. Organisms were grown in only $14 \%$ of the patients. The problems of this delay, however, were inadequate fluid resuscitation in $9 \%$ of the patients who presented with hypotension, and subsequently, a raised serum creatinine in $24 \%$ of the patients. The role of bacterial contamination in duodenal ulcer perforation has been previously analysed by Boey et al, who had concluded that bacterial contamination may be of less consequence than previously thought, even in perforation of upto 2 days duration [25]

\section{Morbidity and mortality}

Eighty four patients had minor wound infection, while 36 had major wound infection and wound dehiscence. Four patients required re-operation for postoperative leak. Two of these survived by resuturing, drainage and performance of a feeding jejunostomy. Three of these 4 patients who leaked (75\%) had a perforation $>1 \mathrm{~cm}$ in size while it was $1.0 \mathrm{~cm}$ in fourth patient. We advocate that a feeding jejunostomy should probably be done in all patients when the perforation is $1 \mathrm{~cm}$ or more in size.

There were 5 deaths in the series (5\%). Mortality rates of 8 $-10 \%$ have been observed in many recent Indian series $[12,18$, 21]. Analysing the details of these 5 patients, we observe that 3 of these patients had unrecordable blood pressure at admission. The fourth and fifth patients had a mean arterial blood pressure of 70 and $93 \mathrm{mmHg}$ respectively. All the 5 patients presented more than 48 hours after perforation. Three patients had perforation of $1.5 \mathrm{~cm}$ and two of them were reoperated due to leak.

\section{Relationship of various risk factors to outcome}

The mean age of patients, who went home without complications (Table 2), was 33.86 years which was significantly different from the mean age of the patients who died or had complications, where it was 41.81 years. No statistically significant difference was observed, however, when only the dead patients were considered (Table 3). This may be because of a smaller number of patients who died in our series. When subjected to logistic regression analysis, age was not found to be a significant factor affecting morbidity or mortality. Age was not found to be a significant risk factor by Boey et al [25], but a significant risk factor by others in cases of NTDUP $[18,21,26]$. The influence of age was significant on the duration of hospital stay (Table 4, Pearson correlation).

The low mortality rate could have also affected other important factors like hypotension and P-O interval. There was a statistically significant difference in the mean arterial pressure of patients who died and those who survived (Table 3). On regression analysis, however, it was not found to be a significant risk factor. Low arterial pressure has been attributed to poor outcome by several authors $[18,25,26]$.

All the five deaths in this series occurred in patients who were operated after 48 hours and this was statistically significant (Table 3). Delay in the operation also resulted in longer hospital stay (Table 4). On regression analysis, again, this was not found to be a significant risk factor. Perforation-operation interval was found to be significant risk factor in many Indian studies, [18, $21,25,27,28]$ but not by others [29]. Most Indian authors have stressed the importance of early operation to improve survival in duodenal perforation. This is largely a preventable cause of mortality.

\section{Serum creatinine}

Serum creatinine was found to be a single independent factor affecting the morbidity and mortality in this study. A similar conclusion was drawn by Ferrara et al from Ohio who had found preoperative serum creatinine to be the most powerful predictor of survival [29]. Serum creatinine was also found to be a significant factor associated with mortality by Mishra et al from India [21]. Serum creatinine also significantly correlated with longer hospital stay in our study.

\section{Size of perforation}

The size of perforation was found to be a significant risk factor in univariate analysis (Table 2, Table 3). It was also found to be an independent variable affecting the length of stay in hospital. When analysed by stepwise logistic regression, the size of perforation was found to be significant risk factor by Rajesh et al [18]. We have found that even large perforations can be repaired satisfactorily with an omental patch. By routinely performing suitable proximal diversion (tube gastrostomy or duodenostomy) along with feeding jejunostomy in patients with perforation of size more than $1 \mathrm{~cm}$, morbidity due to leak is minimized.

\section{Scoring Systems}

The APACHE-II, MPI scoring, and the Jabalpur Score, all seem to allocate lower scores to our patients who have not suffered any complications or death. Results of the Hacettepe scoring system are, however, at variance from the results of the original authors [30]. None of the patients who died had low scores in this system.

When the scoring systems were statistically analysed using receiver operating characteristic (ROC) curves (Table 5), the APACHE-II system and the Jabalpur Scoring System were found to correctly predict morbidity and mortality in our patients. The APACHE II system is widely accepted due to its accurate representation of physiological alterations, using objective measurable parameters. Most consider it the 'gold standard', having been validated in thousands of patients globally. However, the complexities of the APACHE-II and its dependence on sophisticated investigations have prevented its wider use in developing countries. The Jabalpur scoring system is useful because it incorporates perforation-operation interval, which is an important prognostic parameter in developing countries. Moreover, its simplicity ensures objectivity and consistency in data collection. It can be applicable in centers where intensive care facilities are limited. The Jabalpur Scoring system can predict both morbidity and mortality [21].

\section{Conclusions}

Our patients of duodenal ulcer perforation are younger, with a high leak rate and mortality. Serum creatinine and size of perforation are factors linked to poor outcome. Omental patch 
repair is suitable for large perforations in the emergency setting with limited expertise; more data is needed to validate other techniques.

\begin{tabular}{|c|c|c|c|c|}
\hline \multicolumn{5}{|c|}{ Table 5: Statistical analysis of the various scoring systems } \\
\hline Scores & $\begin{array}{c}\text { Area under } \\
\text { the ROC curve }\end{array}$ & $\begin{array}{c}\text { Standard } \\
\text { error }\end{array}$ & $\mathbf{9 5} \%$ CI & Significance \\
\hline $\begin{array}{c}\text { APACHE- } \\
\text { II }\end{array}$ & 0.814 & 0.050 & $0.724-0.885$ & 0.0001 \\
\hline Jabalpur & 0.809 & 0.051 & $0.718-0.881$ & 0.0001 \\
\hline MPI & 0.707 & 0.066 & $0.607-0.794$ & 0.0019 \\
\hline Hacettepe & 0.535 & 0.085 & $0.432-0.635$ & 0.6806 \\
\hline
\end{tabular}

\section{References}

1. Nishida T, Fujita N, Megawa T, Nakahara M, Nakao K. Postoperative hyperbilirubinemia after surgery for gastrointestinal perforation. Surg Today. 2002;32(8):679-684

2. Chen SC, Lin FY, Hsieh YS, Chen WJ. Accuracy of ultrasonography in the diagnosis of peritonitis compared with the clinical impression of the surgeon. Arch Surg. 2000;135(2):170-173.

3. Dandapat MC, Mukherjee LM, Mishra SB, Howlader PC. Gastrointestinal perforations. Indian J Surg. 1991;53:189-193.

4. Shah HK, Trivedi VD. Peritonitis- a study of 110 cases. Indian Practitioner. 1988;41:855-860.

5. Khan S, Khan IU, Aslam S, Haque A. Retrospective analysis of abdominal surgeries at Nepalgunj Medical College, Nepalgunj, Nepal: 2 year's experience. Kathmandu University Medical Journal. 2004;2(4):336343.

6. Penn I. The declining role of surgeon in the treatment of acidpeptic diseases. Arch Surg 1980;115(2):134-135. doi:10.1001/ archsurg.1980.01380020004002

7. Fineberg HV, Pearlman LA. Surgical treatment of peptic ulcer in the United States; trends before and after the introduction of cimetidine. Lancet. 1981;1(8233):1305-1307.

8. Enders KW, Lam YH, Sungh IJY, Yung MY, To KF, Chan AC, et al. Eradicated helicobacter pylori prevents recurrence of ulcer after closure of duodenal ulcer perforation: randomized controlled trial. Ann Surg. 2000;231(2):153-158.

9. Sharma D, Saxena A, Rahman H, Raina VK, Kapoor JP. 'Free omental plug': a nostalgic look at an old and dependable technique for giant peptic perforations. Dig Surg. 2000;17(3):216-218.

10.Gupta S, Kaushik R, Sharma R, Attri A. The management of large perforations of duodenal ulcers. BMC Surg. 2005;5:15.

11.Siu WT, Leong HT, Law BK, Chau CH, Li AC, Fung KH, et al. Laparoscopic repair for perforated peptic ulcer: a randomized controlled trial. Ann Surg. 2002;235(3):313-319.

12.Dorairajan LN, Gupta S, Deo SVS, Chumber S, Sharma LK. Peritonitis in India- a decade's experience. Trop Gastroenterol. 1995;16(1):33-38.
13.Englund R, Fisher R. Survival following perforation of peptic ulcer. Aust NZJ Surg. 1990;60(10):795-800.

14.Coleman JA, Denham MJ. Perforation of peptic ulceration in the elderly. Age Ageing. 1980;9(4):257-261

15.Feliciano DV, Bitondo CG, Burch JM, Mattox KL, Jordan GL Jr, DeBakey ME. Emergency management of perforated peptic ulcers in the elderly patients. Am J Surg. 1984;148(6):764-767.

16.Chan WH, Wong WK, Khin LW, Soo KC. Adverse operative risk factors for perforated peptic ulcer. Ann Acad Med Singapore. 2000;29(2):164167.

17.Wakayama $\mathrm{T}$, Ishizaki $\mathrm{Y}$, Mitsusada $\mathrm{M}$, Takahashi $\mathrm{S}$, Wada $\mathrm{T}$, Fukushima Y, et al. Risk factors influencing the short-term results of gastroduodenal perforation. Surg Today. 1994;24(8):681-687. doi:10.1007/BF01636772

18.Rajesh V, Chandra SS, Smile SR. Risk factors predicting operative mortality in perforated peptic ulcer disease. Trop Gastroenterol. 2003;24(3):148-150.

19.Boey J, Choi SK, Poon A, Alagaratnam TT. Risk stratification in perforated duodenal ulcers: a prospective validation of predictive factors. Ann Surg. 1987;205(1):22-26.

20.Hamby LS, Zweng TN, Strodel WE. Perforated gastric and duodenal ulcer: an analysis of prognostic factors. Am Surg. 1993;59(5):319-323.

21.Mishra A, Sharma D, Raina VK. A simplified prognostic scoring system for peptic ulcer perforation in developing countries. Indian J Gastroenterol. 2003;22(2):49-53.

22.Svanes C, Soreide JA, Skarstein A, Fevang BT, Bakke P, Vollset SE, et al. Smoking and ulcer perforation. Gut. 1997;41(2):177-180.

23.Walt Rkastchinski B, Logan R, Ashley J, Langman M. Rising frequency of ulcer perforation in elderly people in the United Kingdom. Lancet. 1986;1(8479):489-492.

24.Collier DS, Pain JA. Non-steroidal anti-inflammatory drugs and peptic ulcer perforation. Gut. 1985;26(4):359-363.

25.Boey J, Wong J, Ong GB. A prospective study of operative risk factors in perforated duodenal ulcers. Ann Surg. 1982;195(3):265-269.

26.Kulkarni SH, Kshirsagar AY. Simple closure of perforated duodenal ulcer. J Indian Med Assoc. 1998;96(10):309-311.

27.Bodner B, Harrington ME, Kim U. A multifactorial analysis of mortality and morbidity in perforated peptic ulcer disease. Surg Gynecol Obstet. 1990;171(4):315-320.

28.Chou NH, Mok KT, Chang HT, Liu SI, Tsai CC, Wang BW, et al. Risk factors of mortality in perforated peptic ulcer. Eur J Surg. 2000;166(2):149-53.

29.Ferrara JJ, Wanamaker S, Carey LC. Preoperative serum creatinine as a predictor of survival in perforated gastroduodenal ulcer. Am Surg. 1985;51(10):551-555

30.Altaca G, Sayek I, Onat D, Cakmakci M, Kamiloglu S. Risk factors in perforated peptic ulcer disease: comparison of a new score system with the Mannheim Peritonitis Index. Eur J Surg. 1992;158(4):217-221. 